J. Clin. Chem. Clin. Biochem.

Vol. 27, 1989, pp. 605-611

(C) 1989 Walter de Gruyter \& Co. Berlin - New York

\title{
Enzymatic Determination of Lipids in Human Bile without Bilirubin Interference: Reliable Assessment of the Cholesterol Saturation Index (CSI)
}

\author{
By $J$. Aufenanger and $R$. Kattermann \\ Institut für Klinische Chemie, Klinikum Mannheim der Universität Heidelberg
}

(Received May 8/July 19, 1989)

\begin{abstract}
Summary: We describe a simple and rapid, but nevertheless precise and accurate method for the enzymatic determination of the main lipid constituents in human bile. Interfering bile pigments, especially bilirubin are eliminated by the use of aminopropyl bonded phase columns ("Bond-Elut") prior to the enzymatic measurement of cholesterol and lecithin. Intra-assay imprecision was between 3.1 and $4.9 \% \mathrm{CV}$, while the inter-assay figures were rather higher at 4.6 to $7.5 \% \mathrm{CV}$. Recoveries of bile salts, lecithin and cholesterol were between 94 and $103 \%$. In contrast, the direct enzymatic determination in native bile produces falsely low results: lecithin from 5 to $20 \%$, cholesterol from 25 to $40 \%$ of the true value. The results of both enzymatic methods correlated well with commonly accepted procedures for phospholipid and cholesterol determination. When compared with methods of bile lipid analysis involving solvent extraction, the column separation followed by enzymatic determination has the advantage of being simpler and less time consuming, without need of highcost equipment, e.g. gas chromatography.
\end{abstract}

\section{Introduction}

For several reasons, bile lipid analysis has attracted considerable interest during the last decade. Firstly, the reliable determination of cholesterol, lecithin and bile salts is a fundamental prerequisite for the assessment of lithogenic bile according to Carey (1). Secondly, pathobiochemical research has focussed on biliary lipid secretion, which not only shows marked daily fluctuationș during the fed and fasted state (2), but is also greatly influenced by age and obesity (3) and by contraceptive steroids (4). Finally, the increasing application of lithotriptic gallstone therapy followed by chenodeoxy-/ursodeoxycholic acid treatment will certainly stimulate the request for bile lipid analysis in the clinical chemical laboratory (5).

The separation and quantitative estimation of neutral and polar lipid fractions in bile by solvent extraction has been the subject of numerous reports. A chloroform-methanol extracting according to Folch et al. (6) is used by most investigators. This method is easily applied to serum or tissue extraction, but considerable losses of phospholipids occur in the upper methanolwater phase, particularly in frozen bile samples with a high bile salt content, as already reported by Bolton et al. (7).

More recently, enzymatic methods were introduced for the determination of lecithin $(8,9)$ and cholesterol $(10,11)$ in human bile. Originally, the so-called "catalase-method" according to Roeschlau et al. (12) was used by the latter authors $(10,11)$. In the meantime, this procedure for enzymatic cholesterol determination has been generally replaced by the phenol/aminoantipyrine method, the characteristics of which have been described in detail by Kattermann et al. (13). In our first attempts at the enzymatic analysis in human gall bladder bile we found a gross interference by bilirubin in the determination of both cholesterol and lecithin. 
Recently, a method was described by Kaluzny et al. (14) for the rapid separation of lipid classes, utilizing aminopropyl-bonded phase columns ("Bond-Elut"). We have successfully applied this method to human bile specimens, with subsequent enzymatic determination of cholesterol and lecithin. When compared with existing methods of bile lipid analysis there are several advantages of the method described here: no sample pretreatment, rapid elution, enzymatic determination of lecithin and cholesterol without bilirubin interference, high reliability of results and low costs of both operator time and reagents. The "Bond-Elut"procedure may therefore be the method of choice if large numbers of bile samples are to be analysed in the routine or in the specialized laboratory.

\section{Materials and Methods}

The aminopropyl-bonded phase columns "Bond Elut/Analytichem No. 611101" were purchased from ICT, Frankfurt/M. Total cholesterol was measured by a manual cholesterol oxidase method (Boehringer Mannheim, No. 8254015 ), lecithin by a manual choline oxidase method after cleavage with phospholipase D (WAKO Chemicals GmbH, No. 27954009). Total lipid phosphorus in bile was determined according to Bartlett (15) after acidic combustion at $180^{\circ} \mathrm{C}$. Total bile salts were measured in diluted samples $(1: 10$ or $1: 20)$ by use of the enzymatic method first described by Iivata \& Yamasaki (16) and now commercially available as Sterognost-3 $\alpha$-Pho from Nyegaard/Oslo. The determination of total cholesterol by solvent extraction, saponification and digitonin precipitation was carried out according to Sperry \& Webb (17). All other solvents and reagents in this study were analytical grade. Sodium cholate and chenodeoxycholate were available from SERVA GmbH, Heidelberg. Bile samples were generally taken from the gall bladder during cholecystectomy. For the purpose of quality control, residual amounts of human bile were pooled, centrifuged for $15 \mathrm{~min}$ at $3000 \mathrm{~g}$ and the supernatant frozen in aliquots of $200 \mu \mathrm{l}$ at $-20^{\circ} \mathrm{C}$ ("Pool-bile").

\section{Separation procedure}

The "Bond-Elut"-columns are twice eluted with $3 \mathrm{ml} n$-hexane and aspirated to dryness for $5-10 \mathrm{~min}$. Thereafter, $100 \mu \mathrm{l}$ of bile, containing less than $20 \mathrm{mmol} / 1$ total cholesterol, are pipetted on to the top of the column. Since we were only interested in the cholesterol and lecithin fraction, the original procedure of Kaluzny et al. (14) with 8 different solvent mixtures was simplified. First, cholesterol was eluted with $3 \mathrm{ml}$ chloroformisopropanol $(3+1$, by vol. $)$ in a glass-stoppered centrifuge tube. Afterwards, $3 \mathrm{ml}$ methanol were applied to the column and lecithin was eluted into the same centrifuge tube. The combined, clear eluates were taken to dryness at $50^{\circ} \mathrm{C}$ (Rotavapor, Büchi or Speed-Vac. NUNC) and redissolved in $500 \mu$ l of isopropanol.

\section{Cholesterol determination}

Pipette $20 \mu \mathrm{l}$ of the standard and of the isopropanol phase into a plastic cuvette $(\mathrm{d}=1 \mathrm{~cm})$, add $1000 \mu \mathrm{l}$ CHOD/PAP reagent directly, keep for $10 \mathrm{~min}$ at room temperature and measure the red colour at $546 \mathrm{~nm}$ against the reagent blank.

Calculation on the basis of the cholesterol standard ("Precimat", Boehringer; $2.59 \mathrm{mmol} / \mathrm{l})$ :

$$
\frac{A_{\text {sample }}}{A_{\text {standard }}} \times 12.93=\text { cholesterol in bile }(\mathrm{mmol} / \mathrm{l})
$$

\section{Lecithin determination}

Pipette $20 \mu \mathrm{l}$ of the standard and of the isopropanol phase into a plastic cuvette $(\mathrm{d}=1 \mathrm{~cm})$. Add $1000 \mu \mathrm{l}$ Phospholip B reagent directly, keep $20 \mathrm{~min}$ at room temperature and measure the red colour at $546 \mathrm{~nm}$ against the reagent blank. Calculation on the basis of the lecithin standard (WAKO; $3.87 \mathrm{mmol} / \mathrm{l}$ ):

$$
\frac{\mathrm{A}_{\text {sample }}}{\mathrm{A}_{\text {standard }}} \times 19.35=\text { lecithin in bile }(\mathrm{mmol} / \mathrm{l}) \text {. }
$$

\section{Results and Discussion}

\section{Imprecision}

The intra-assay imprecision of the Bond-Elut procedure was 4.40 and $4.95 \% \mathrm{CV}$ for the lecithin and cholesterol determination, respectively. The direct enzymatic measurement of total bile acids in diluted pool-bile exhibited a coefficient of variation of only $3.07 \%$ (see tab. 1a).

Tab. 1. Imprecision of the enzymatic methods for bile lipid analysis using human pool bile.

\begin{tabular}{|c|c|c|c|c|}
\hline \multirow[t]{2}{*}{ Imprecision } & \multicolumn{2}{|c|}{$\begin{array}{l}\text { a) Within run } \\
(\mathrm{n}=20)\end{array}$} & \multicolumn{2}{|c|}{$\begin{array}{l}\text { b) Between run } \\
(n=60)\end{array}$} \\
\hline & $\begin{array}{l}\text { Mean } \\
\text { mmol/1) }\end{array}$ & $\begin{array}{l}\mathrm{CV} \\
(\%)\end{array}$ & $\begin{array}{l}\text { Mean } \\
(\mathrm{mmol} / \mathrm{l})\end{array}$ & $\begin{array}{l}\mathrm{CV} \\
(\%)\end{array}$ \\
\hline Bile salts & 66.5 & 3.07 & 70.2 & 5.32 \\
\hline Lecithin & 18.3 & 4.40 & 18.5 & 5.67 \\
\hline Cholesterol & 7.45 & 4.95 & 8.02 & 7.46 \\
\hline
\end{tabular}

a) $=$ within run; b) $\rightleftharpoons$ between run over 6 months.

The inter-assay imprecision was calculated from 60 analyses of each parameter over a period of 6 months. As was to be expected, the CVs, at 4.63 and $7.46 \%$ (see tab. 1b), were somewhat higher than those for intra-assay imprecision. The concentrations and relative proportions of bile salts, lecithin and cholesterol are in close agreement with reported values for human gall bladder bile.

\section{Accuracy}

The analytical accuracy of the Bond-Elut procedure was assessed by a recovery experiment using human pool-bile. In order to avoid organic solvents, cholesterol and phospholipids were introduced in the form of low-density lipoprotein (LDL) after ultracentrifugal isolation. The recovery of various amounts of LDL added to pool bile was excellent (see tab. 2). The same was true for the direct determination of bile salts after addition of various amounts of sodium cholate (103 mmol/l in water). As a whole, our results represent an accurate enzymatic determination of bile salts, lecithin and cholesterol in the physiological range in human hepatic or gall bladder bile. 
Tab. 2. Analytical recovery of the Bond-Elut procedure. Various amounts of human low-density lipoprotein (LDL) containing $30.4 \mathrm{mmol} / 1$ cholesterol and $10.2 \mathrm{mmol} / \mathrm{l}$ lecithin were added to pool bile (bilirubin content $=1.1$ $\mathrm{mmol} / \mathrm{l})$. In the case of bile salts, pool bile was supplemented with sodium cholate, followed by direct enzymatic determination in the diluted sample.

\begin{tabular}{lcrrr}
\hline Analyte & $\begin{array}{l}\text { Native } \\
\text { bile } \\
(\mu \mathrm{mol} / 1)\end{array}$ & $\begin{array}{r}\text { Added } \\
(\mu \mathrm{mol})\end{array}$ & $\begin{array}{r}\text { Found } \\
(\mu \mathrm{mol})\end{array}$ & \multicolumn{1}{l}{ Recovery } \\
\hline Cholesterol & 4.3 & 15.2 & 14.3 & 94.1 \\
$\quad$ (after Bond-Elut & 4.3 & 7.6 & 7.6 & 100.0 \\
extraction & 4.3 & 3.8 & 3.9 & 102.6 \\
Lecithin & 8.7 & 5.1 & 5.3 & 103.9 \\
$\quad$ (after Bond-Elut & 8.7 & 3.8 & 3.6 & 94.7 \\
extraction) & 8.7 & 2.6 & 2.3 & 88.4 \\
& 8.7 & 1.3 & 1.3 & 100.0 \\
Bile salts & 36.3 & 103.0 & 100.1 & 97.2 \\
& 36.3 & 77.3 & 79.7 & 103.1 \\
& 36.3 & 51.5 & 49.3 & 95.7 \\
\hline
\end{tabular}

\section{Specificity and interferences}

a) Bile salts are attacked specifically at the $3 \alpha$-hydroxy-group by hydroxy steroid dehydrogenase from Ps. testosteroni (16). No cross-reaction is observed with $\mathrm{C}_{19^{-}}$or $\mathrm{C}_{20}$-steroids in bile, because the $3 \alpha$-hydroxy group in these compounds is protected by glucuronidation or sulfation. In order to obtain complete reaction within $15 \mathrm{~min}$ it was found practical to dilute the native bile samples 10 -fold. Under these conditions linearity is observed up to $250 \mathrm{mmol} / \mathrm{l}$.

b) The enzymatic determination of choline-containing phospholipids in bile (mainly lecithin) was described in detail by Qureshi et al. (8) and by Gurantz et al. (9). The method was found to be simple, sensitive and reproducible with linear recoveries of lecithin. Besides lysolecithin and sphingomyelin, which are also split by phospholipase $\mathrm{D}$, it must be noted that the choline oxidase could conceivably react with any free choline which might be present in the bile samples. The interference by bile pigments, especially bilirubin, depends on the absolute concentration of these pigments, which may cause a loss of up to $30 \%$ of the chromophore (fig. 1). Therefore, the latter authors proposed an overnight photodegradation of the samples (9). This rather cumbersome procedure can be overcome by the Bond-Elut method as described here (see fig. 1 and tab. 3).

c) Even more important is the bilirubin interference in the direct enzymatic cholesterol determination, using the phenol/aminoantipyrine method. The effect of elevated bilirubin on the detection of hydrogen peroxide in this reaction has already been described by Witte et al. (18). When analysing icteric serum sam-

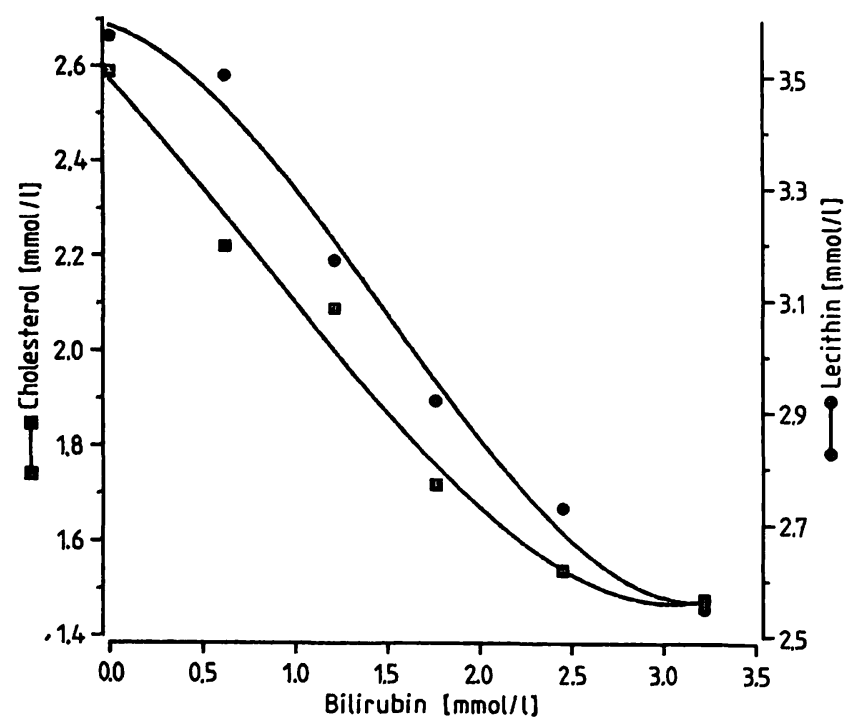

Fig. 1. Bilirubin interference with the enzymatic determination of cholesterol and lecithin. Decrease of absorbance at $546 \mathrm{~nm}$ and hence of the apparent standard concentration with increasing bilirubin.

Tab. 3. Influence of bilirubin on bile lipid analysis in 3 samples of human gall bladder bile (A, B, C). The enzymatic determination was carried out as described above with $20 \mu \mathrm{l}$ of the clear isopropanol phase (Bond-Elut) or with $20 \mu \mathrm{l}$ native bile, respectively. The effect of bilirubin in lecithin-rich bile samples decreases with the degree of dilution.

\begin{tabular}{lllllll}
\hline Bile & $\begin{array}{l}\text { Bilirubin } \\
(\mathrm{mmol} / \mathrm{l})\end{array}$ & $\begin{array}{l}\text { Cholesterol } \\
(\mathrm{mmol} / \mathrm{l})\end{array}$ & & \multicolumn{2}{l}{$\begin{array}{l}\text { Lecithin } \\
\text { (mmol/l) }\end{array}$} \\
\cline { 3 - 4 } \cline { 5 - 7 } & & $\begin{array}{l}\text { Bond } \\
\text { Elut }\end{array}$ & $\begin{array}{l}\text { native } \\
\text { bile }\end{array}$ & & $\begin{array}{l}\text { Bond } \\
\text { Elut }\end{array}$ & $\begin{array}{l}\text { native } \\
\text { bile* }\end{array}$ \\
\hline A & 1.07 & 4.15 & 3.15 & & 8.3 & $\left.6.7^{\mathrm{a}}\right)$ \\
B & 1.22 & 7.44 & 4.43 & & 18.5 & $\left.15.2^{\mathrm{b}}\right)$ \\
C & 2.00 & 13.1 & 10.2 & & 37.2 & $\left.36.3^{\mathrm{C}}\right)$ \\
\hline
\end{tabular}

* Native bile diluted

a) $\left.1: 2,{ }^{b}\right) 1: 5$ and $^{c}$ ) $1: 10$

ples, these authors observed false positive or false negative effects, due to bilirubin concentrations between 140 and $420 \mu \mathrm{mol} / \mathrm{l}$, and related to differences in reagent composition. These complex effects were attributed partly to spectral overlap and partly to chemical interference, i.e. the destruction of a peroxidase reaction intermediate. In gall bladder bile there are two further complicating factors, i.e. the presence of a mixture of bilirubin diglucuronide, biliverdin and other tetra- or dipyrroles, together with total bilirubin concentrations up to $2500 \mu \mathrm{mol} / \mathrm{l}$ without albumin binding.

For a better insight into the mode of bilirubin interference we performed two types of experiments. Firstly, three human bile samples (A, B, C) with different bilirubin contents were analysed for cholesterol and lecithin either directly with sample-blank- 
correction or by the Bond-Elut procedure (see tab. 3 ). When using native bile the results were $25-40 \%$ lower for cholesterol and 5-20\% for lecithin compared with the Bond-Elut values. These data are in good agreement with a former communication of Bolton et al. (19), who found consistently lower results with the enzymatic procedure (average $-23 \%$ ) when compared with the GLC method.

Secondly, a particular bile sample with high bilirubin and low lipid concentrations was diluted with saline to obtain bilirubin concentrations between 0.6 and $3.0 \mathrm{mmol} / \mathrm{l}$ (see fig. 1). Aliquots $(20 \mu \mathrm{l})$ of these samples were added to $1000 \mu \mathrm{l}$ of the cholesterol or lecithin reagent and the absorbance was read at 546 nm against a reagent blank. Thereafter, $40 \mu l$ of the cholesterol standard or $20 \mu \mathrm{l}$ of the lecithin standard were added to the cuvette and the increase of absorbance was registered. As can be seen from figure 1 the apparent standard concentrations decreased continuously, depending on the absolute bilirubin content of the cuvette.

Finally, we registered the differential spectra of these cuvettes against the corresponding sample blanks in a recording spectrophotometer (UV/VIS-Lambda 15, Perkin u. Elmer, Überlingen). A net decrease of absorbance in the bilirubin-containing cuvettes was observed in both peroxidase reactions, which result in the formation of the same dye [4-( $p$-benzochinone)-
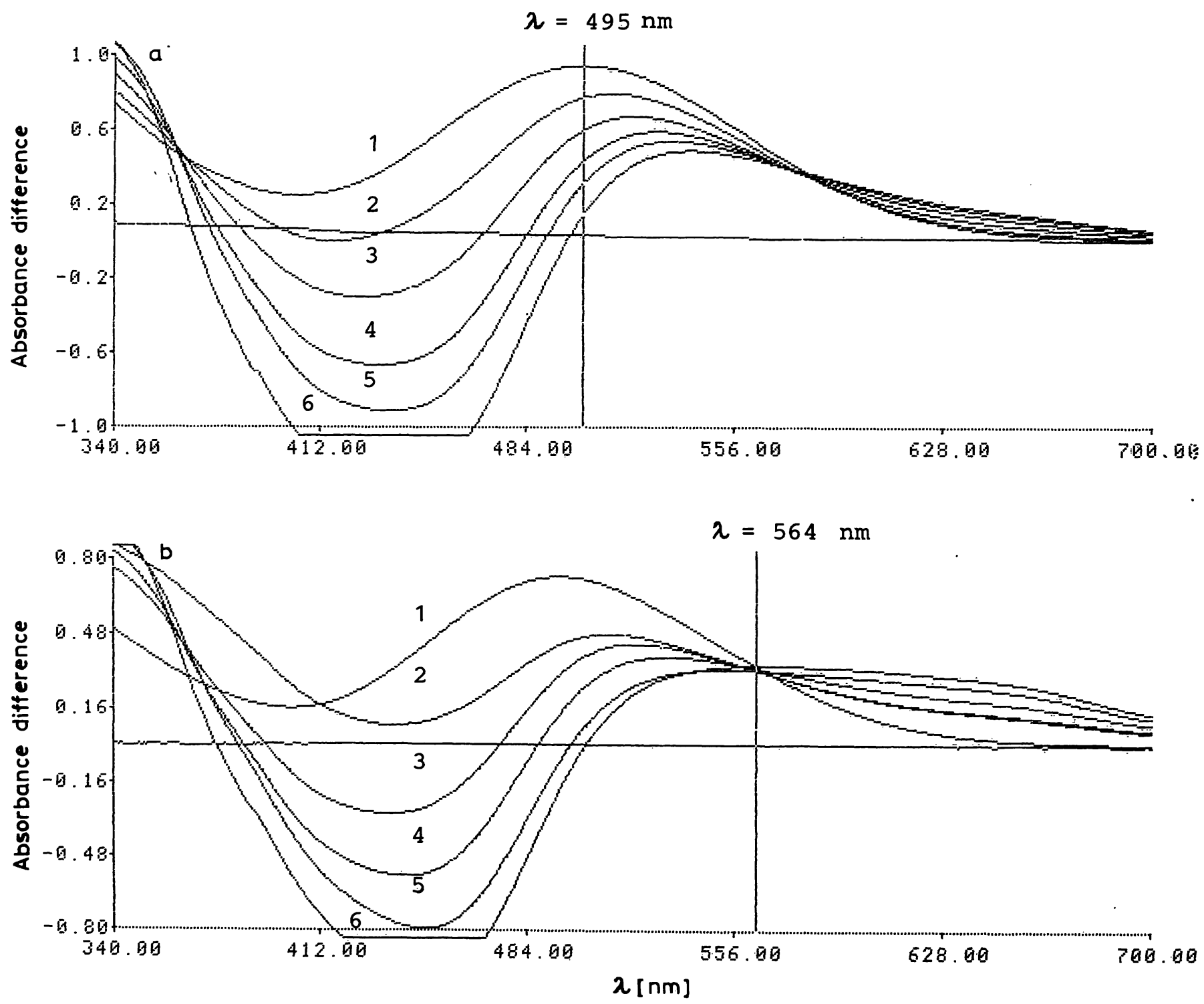

Fig. 2. Difference spectra of the phenol/aminoantipyrine reaction in the presence of increasing concentrations of bile pigments. $\mathrm{a}=$ Enzymatic cholesterol determination with $40 \mu \mathrm{l}$ of the cholesterol standard $(2.59 \mathrm{mmol} / \mathrm{l})$.

$\mathrm{b}=$ Enzymatic reaction of lecithin with $20 \mu \mathrm{l}$ of the lecithin standard $(3.87 \mathrm{mmol} / \mathrm{l})$.

The cuvettes contained $1000 \mu \mathrm{l}$ cholesterol or lecithin reagent and $20 \mu \mathrm{l}$ of the bile sample with the following bilirubin concentrations (mmol/1):

$1=0$ (saline); $2=0.62 ; 3=1.21 ; 4=1.76 ; 5=2.45 ; 6=3.22$.

Measurement of absorbance against a blank cuvette with $1000 \mu \mathrm{l}$ distilled water and $20 \mu \mathrm{l}$ of the corresponding bile sample. 
monoimino-phenazone]. Simultaneously, the maximum absorbance shifts from 500 to $550 \mathrm{~nm}$, whilst the visible colour changes from red to brown-green. It remains questionable as to whether correct results are obtained when the absorbance is read at the apparent isosbestic point of $564 \mathrm{~nm}$ (see fig. 2).

\section{Correlation with other methods}

We compared the Bond-Elut procedure for cholesterol with the well established digitonin method of Sperry \& Webb (9). The results of 103 bile sample analyses in the concentration range up to $30 \mathrm{mmol} / \mathrm{l}$ cholesterol were evaluated by nonparametric analysis according to Passing \& Bablok (20). As can be seen from figure 3 , both methods correlate well $(r=0.96)$ in spite of a $10 \%$ deviation (slope $=0.912$ ) from the line of identity, due to the loss of cholesterol in the extraction step of the digitonin procedure.

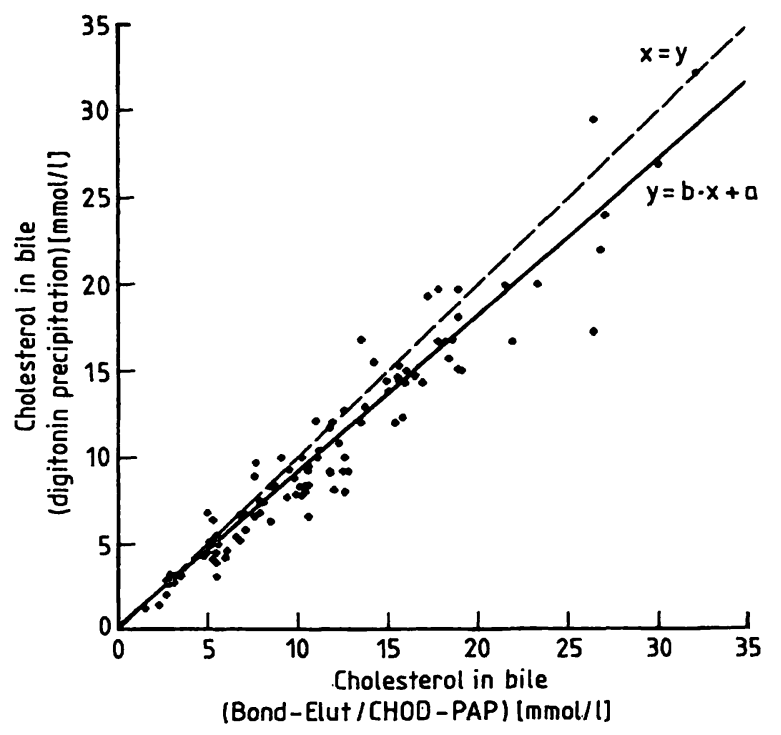

Fig. 3. Comparison of the cholesterol digitonin procedure (y) with the cholesterol oxidase $p$-amino-phenazone (PAP) method (x) after Bond-Elut separation using human bile samples.

$(\mathrm{n} \doteq 103, \mathrm{y}=0.91 \mathrm{x}-0.17, \mathrm{r}=0.963)$.

The lecithin determination following the Bond-Elut separation was compared with the measurement of total phospholipids in 44 samples of native bile. The regression analysis according to Passing \& Bablok (20) revealed an excellent correlation of both methods with a slope of 0.949 , i. e. the values from the BondElut procedure were about $5 \%$ lower (see fig. 4). This systematic deviation may be due to the existence of phospholipids other than lecithin and/or the presence of inorganic phosphate which is a normal constituent of human bile (8).

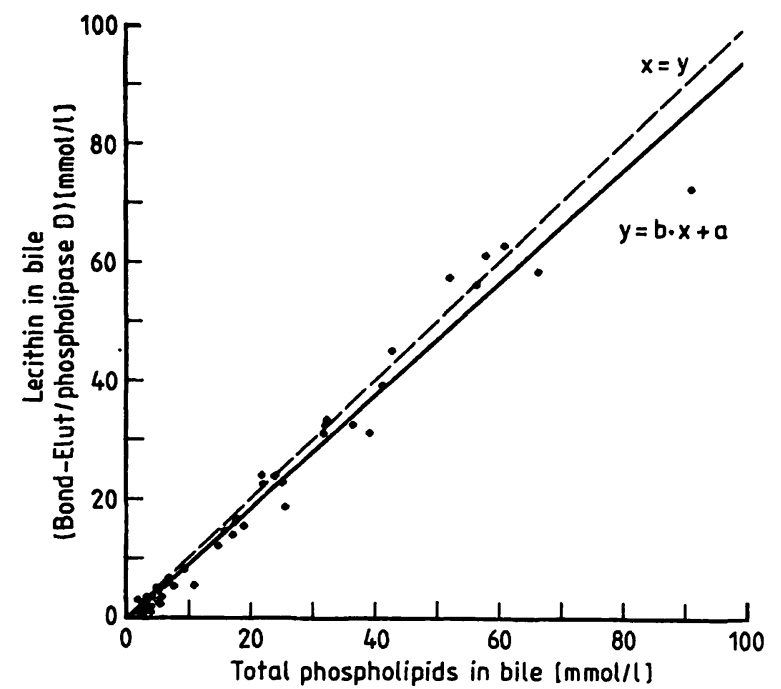

Fig. 4. Comparison of the enzymatic lecithin test (y) after Bond-Elut separation with the photometric determination of total phospholipids after wet combustion $(x)$ using human bile samples.

$(n=44, y=0.949 x-0.62, r=0.985)$

Tab. 4. Reference values of bile lipids and cholesterol saturation index as obtained in each of 15 male and female bile samples.

\begin{tabular}{lcc}
\hline Analyte/mol \% & \multicolumn{2}{c}{ Reference values $(\overline{\mathrm{x}} \pm 2 \mathrm{~s})$} \\
\cline { 2 - 3 } & \multicolumn{1}{c}{ Male $(\mathrm{n}=15)$} & Female $(\mathrm{n}=15)$ \\
\hline Cholesterol & $6.8 \pm 3.0$ & $7.1 \pm 2.7$ \\
Lecithin & $22.5 \pm 5.6$ & $23.5 \pm 8.4$ \\
Bile salts & $70.6 \pm 7.0$ & $69.1 \pm 20.2$ \\
\hline Cholesterol saturation & $99.2 \pm 37.8$ & $103.7 \pm 30.3$ \\
index & & \\
\hline
\end{tabular}

\section{Reference values}

In general, the bile samples were taken from gallstone patients undergoing cholecystectomy. Also, we obtained 15 bile samples each from male and female patients who had died after a cerebral or cardiovascular attack. Assuming a normal distribution of results, we calculated the reference values given in table 4. The figures fit well with the results of other authors $(1-4)$.

\section{Cholesterol saturation index}

On the basis of an accurate enzymatic lipid analysis as described above, the cholesterol saturation index can easily be calculated by a microcomputer program according to Kuroki et al. (21). This program was adapted to a personal computer in our laboratory. It allows a quick and reliable calculation of the molar percentages of the three main constituents, of the 


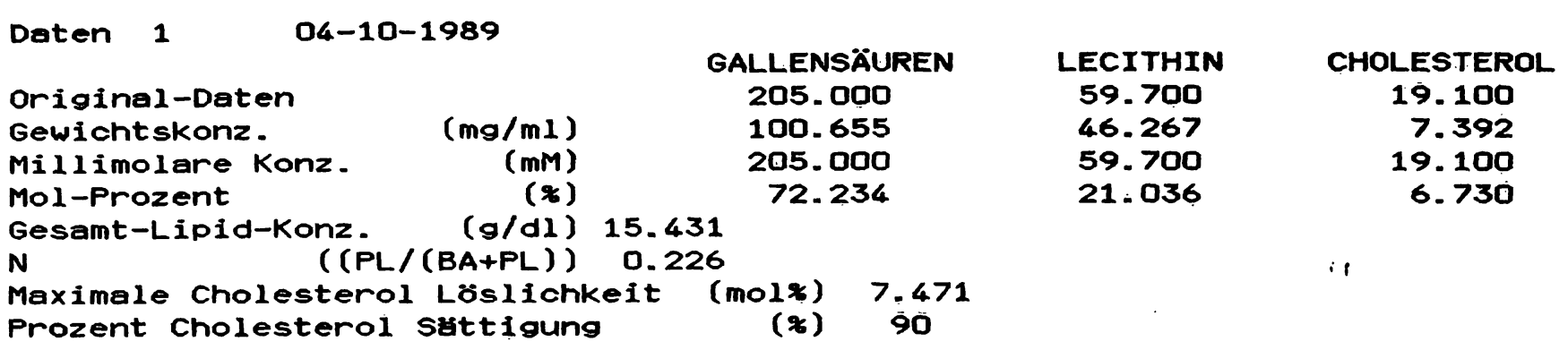

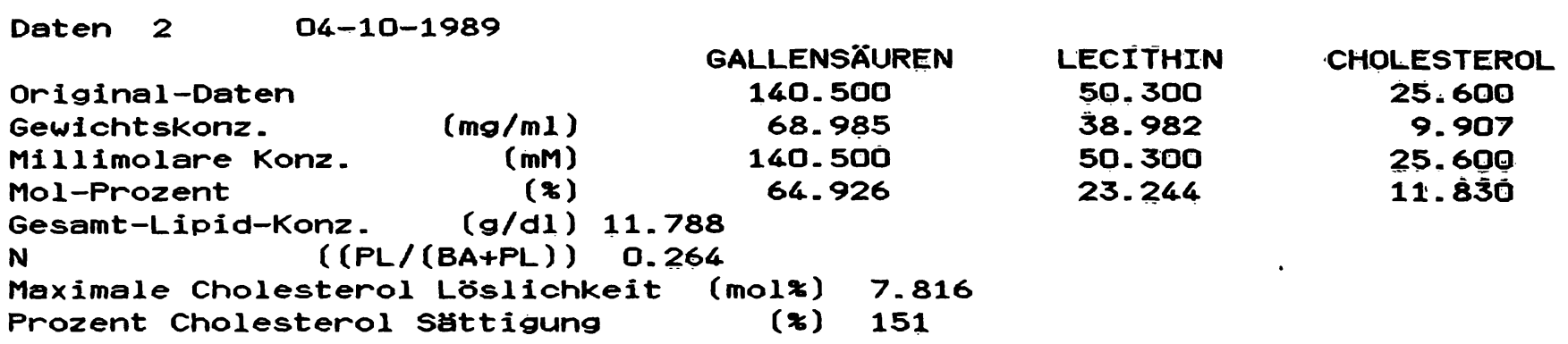

Fig. 5. Original print-out of two bile samples with a normal and an elevated cholesterol saturation index, using the computer program of Kuroki et al. (21).

Daten Data

Original-Daten

Gewichtskonz. (mg/ml)

Millimolare Konz. (mM)

Mol-Prozent (\%)

Gesamt-Lipid-Konz. (g/dl)

$\mathrm{N}((\mathrm{PL} /(\mathrm{BA}+\mathrm{PL}))$

Maximale Cholesterol-Löslichkeit

(mol \%) sents $100 \%$ solubility

\section{Original data}

Mass concentration $(\mathrm{g} / \mathrm{l})$

Millimolar concentration (mmol/l)

Percentage of total (bile acids + lecithin + cholesterol) millimolar concentration (mol \%)

Total lipid concentration; multiply by 10 to obtain $\mathrm{g} / \mathrm{l}$

Ratio of the millimolar concentration of lecithin to bile acids plus lecithin

Maximal cholesterol solubility, calculated by the program; the value given in $\mathrm{mol} \%$ repre-

Percent cholesterol saturation calculated as cholesterol, actual concentration fraction (mol \%)

Bile acids

Gallensäuren cholesterol, maximal solubility (mol \%) $\times 100(\%)$

maximal cholesterol solubility and of bile supersaturation with regard to the total lipid concentration of the individual bile sample. as described by Carey (1).
The original print-out of two bile samples with normal and elevated cholesterol saturation index is given in figure 5 .

\section{References}

1. Carey, M. C. (1978) Critical tables for calculating the cholesterol saturation of native bile. J. Lipid. Res. 19, 945955.

2. Pattinson, N. R. \& Chapman, B. A. (1986) Distribution of biliary cholesterol between mixed micelles and nonmicelles in relation to fasting and feeding in humans. Gastroenterology $91,697-702$.

3. Leiß, O. \& Bergmann, K. v. (1985) Comparison of biliary lipid secretion in non-obese cholesterol gallstone patients with normal, young, male volunteers. Klin. Wochenschr. $63,1163-1169$.

4. Kern, F. \& Everson, G. T. (1987) Contraceptive steroids increase cholesterol in bile: mechanisms of action. J. Lipid. Res. 28, 828-839.
5. Sackmann, M., Delius, M., Sauerbruch, T., Holl, J., Weber, W., Ippisch, E., Hagelauer, U., Wess, O., Hepp, W., Brendel, W. \& Paumgartner, G. (1988) Shock-wave lithotripsy of gall-bladder stones. New Engl. J. Med. 318, 393-397.

6. Folch, J., Lees, M. \& Sloane-Stanley, G. H. (1957) A simple method for the isolation and purification of total lipids from animal tissues. J. Biol. Chem. 226, 497-509.

7. Bolton, C. H., Low-Beer, T. S., Pomare, E. W., Wicks, A. C. B., Yeates, J. \& Heaton, K. W. (1978) A simplified procedure for the analysis of cholesterol, phospholipids and bile salts in human bile. Clin. Chim. Acta 83, 177-181.

8. Qureshi, M. Y., Murphy, G. M. \& Dowling, R. H. (1980) The enzymatic determination of total phospholipids in bile and bile-rich duodenal aspirates. Clin. Chim. Acta 105, "407-410. 
9. Gurantz, D., Laker, M. F. \& Hofmann, A. F. (1981) Enzymatic measurement of choline-containing phospholipids in bile. J. Lipid Res. 22, 373-376.

10. Roda, A., Festi, D., Sama, C., Mazzella, G., Aldini, R., Roda, E. \& Barbara, L. (1975) Enzymatic determination of cholesterol in bile. Clin. Chim. Acta 64, 337-341.

11. Fromm, H., Amin, P., Klein, H. \& Kupke, I. (1980) Use of a simple enzymatic assay for cholesterol analysis in human bile. J. Lipid Res. 21, 259-261.

12. Röschlau, P., Bernt, E. \& Gruber, W. (1974) Enzymatische Bestimmung des Gesamt-Cholesterins im Serum. J. Clin. Chem. Clin. Biochem. 12, 403-407.

13. Kattermann, R., Kupke, I. \& Borner, K. (1983) Vorläufig ausgewählte Methode für die enzymatische Bestimmung des Gesamt-Cholesterins im Serum. J. Clin. Chem. Clin. Biochem. 21, 347-355.

14. Kaluzny, M. A., Duncan, L. A. \& Merritt, M. V. (1985) Rapid separation of lipid classes in high yield and purity using bonded phase columns. J. Lipid Res. 26, 135-140.

15. Bartlett, G. R. (1959) Phosphorus assay in column chromatography. J. Biol. Chem. 234, 466-468.
16. Iwata, T. \& Yamasaki, K. (1964) Enzymatic determination and thin-layer chromatography of bile acids in blood. J. Biochemistry (Tokyo) 56, 424-431.

17. Sperry, W. M. \& Webb, M. (1950) A revision of the Schoenheimer-Sperry method for cholesterol determination. J. Biol. Chem. 187, 97-110.

18. Witte, D. L., Brown, L. F. \& Feld, R. D. (1978) Effects of bilirubin on detection of hydrogen peroxide by use of peroxidase. Clin. Chem. 24, 1778-1782.

19. Bolton, C. H., Nicholls, J. S. \& Heaton, K. W. (1980) Estimation of cholesterol in bile: assessment of an enzymatic method. Clin. Chim. Acta 105, 225-230.

20. Passing, H. \& Bablok, W. (1983) A new biometrical procedure for testing the equality of measurements from two different analytical methods. J. Clin. Chem. Clin. Biochem. $21,709-720$.

21. Kuroki, S., Cohen, B. I., Carey, M. C. \& Mosbach, E. H. (1986) Rapid computation with the personal computer of the percent cholesterol saturation of bile samples. J. Lipid Res. $27,442-446$.

Prof. Dr. R. Kattermann Institut für Klinische Chemie P.O. B. 100023

D-6800 Mannheim 
